\title{
Estatus de la vitamina D en sepsis en la Unidad Cuidados Intensivos Adultos**
}

Vitamin D status in sepsis in the Adult Intensive Care Unit Status da vitamina D na sepse na Unidade de Terapia Intensiva Adulto

Héctor Antonio López Morán, ${ }^{*}$ Arturo Razcón Echeagaray, ${ }^{\ddagger}$ Luis Barrientos Quintanilla, ${ }^{\S}$ Víctor Manuel Sánchez Nava, " Carlos Eduardo Chávez Pérez§

\section{RESUMEN}

Introducción: En la actualidad se ha dado gran importancia al estudio de vitaminas $C$ en sepsis. Sin embargo, especialmente en el contexto de cuidados intensivos, existe evidencia limitada, pero significativa de la elevada prevalencia de la deficiencia de vitamina $D$ en los enfermos con sepsis y choque séptico correlacionándose con la gravedad y la probabilidad de disfunción orgánica.

Material y métodos: Estudio retrospectivo, monocéntrico, observacional y descriptivo, muestra a conveniencia en un hospital de tercer nivel. Se analizó un total de 492 pacientes, de los cuales 105 cursaron con el diagnóstico de sepsis, de éstos, 30 contaron con medición de vitamina D. La edad media fue de 56 años, con predominio del sexo masculino (70\%), antecedentes de patología oncológica (26.7\%) e inmunosupresión (30\%). Al ingreso a la unidad de cuidados intensivos $73.3 \%$ se encontraron en estado de choque, $70 \%$ bajo ventilación mecánica, con un promedio en las escalas de mortalidad de 16 puntos en APACHE II con $25 \%$ de mortalidad de ocho puntos en SOFA con $15-20 \%$ de mortalidad. De acuerdo con los niveles de vitamina $D$, se encontraron dos grupos: insuficiencia (menor de $10 \mathrm{ng} / \mathrm{mL}$ ) y deficiencia (mayor de $10 \mathrm{ng} / \mathrm{mL}$ ). Resultados: No se observó diferencia significativa en edad ( $p=0.724)$, estancia intrahospitalaria $(p=0.755)$, SOFA $(p=0.241)$. Existe significancia estadística en APACHE II con un puntaje medio de 19.5 puntos en el grupo menor de $10 \mathrm{ng} / \mathrm{mL}$ (mortalidad esperada de $25 \%$ ) y de 14.3 puntos en el grupo mayor de $10 \mathrm{ng} / \mathrm{mL}$ (mortalidad esperada de 15\%). La mortalidad se estima en $42.9 \%$ en el grupo menor de 10 y de 12.5 en el grupo mayor de 10, pero no es significativo estadísticamente. Conclusiones: No existe correlación con un valor estadísticamente significativo entre los niveles de vitamina D y días de estancia intrahospitalaria. El porcentaje de defunción de los pacientes con valor inferior a $10 \mathrm{ng} / \mathrm{mL}$ fue de $42.9 \%$ a diferencia de los pacientes con valor superior a $10 \mathrm{ng} / \mathrm{mL}$ de $12.5 \%$, que no alcanza un valor estadísticamente significativo; sin embargo, la población estudiada es reducida, por lo que sólo se requiere aumentar el tamaño de muestra para obtener un valor estadísticamente significativo.

Palabras clave: Sepsis, vitamina D, mortalidad.

\section{ABSTRACT}

Introduction: Nowadays, Vitamin $C$ research in sepsis has been of great importance. However, and especially in the critical care setting, there's limited but significant evidence about the high prevalence of vitamin $D$ deficiency in sepsis and septic shock patients; correlating with the severity and the organ dysfunction risk.

Material and methods: Retrospective study, monocentric, observational and descriptive, sample taken by convenience. 492 patients were analyzed, which 105 had sepsis diagnosis, and 30 of these patients had vitamin D quantification. The median age was 56 years, predominantly male (70\%), the main medical history were oncologic illness, immunosuppression. At the time of intensive care unit admission $73.3 \%$ were in shock state, $70 \%$ on mechanical ventilation, with a mean mortality score of 16 points (APACHE // score, $25 \%$ mortality risk), and 8 points in the SOFA score (15-20\% mortality risk. According with the vitamin D levels, 2 groups were found: Insufficiency (less than $10 \mathrm{ng} / \mathrm{mL}$ ) and deficiency (more than $10 \mathrm{ng} / \mathrm{mL}$ ).

** Concurso Académico de Investigación «Dr. Mario Shapiro» 2020.

* Hospital Ángeles Valle Oriente.

‡ Hospital San José-Hospital Metropolitano

$\S$ Hospital San Jose e Instituto Mexicano del Seguro Social.

I Hospital San José y Hospital Zambrano Hellion.

Recibido: 16/10/2020. Aceptado: 27/10/2020.

Citar como: López MHA, Razcón EA, Barrientos QL, Sánchez NVM, Chávez PCE. Estatus de la vitamina $D$ en sepsis en la Unidad Cuidados Intensivos Adultos. Med Crit. 2021;35(2):65-78. https://dx.doi.org/10.35366/99526

www.medigraphic.com/medicinacritica
Results: There was no significant age difference $(p=0.724)$, length of stay difference $(p=0.755)$, SOFA $(p=0.241)$. There is statistically significance on the APACHE // scores, with a mean score of 19.5 points in the less than $10 \mathrm{ng} /$ $m L$ group (mortality risk 25\%), and 14.5 points in the greater than $10 \mathrm{ng} / \mathrm{mL}$ group (mortality risk 15\%). Mortality estimation was $42.9 \%$ in the less than 10 $\mathrm{ng} / \mathrm{mL}$ group, and $12.5 \%$ in the greater than $10 \mathrm{ng} / \mathrm{mL}$ group, however, this was not statistically significant data.

Conclusions: There is no statistically significant correlation between vitamin $D$ levels and hospital length of stay. Mortality was higher in patients with vitamin $D$ levels lesser than $10 \mathrm{ng} / \mathrm{mL}$ (42.9\%), and $12.5 \%$ mortality in those with levels greater than $10 \mathrm{ng} / \mathrm{mL}$. However the study sample is small, it will be necessary to increase the number of patients in order to obtain more statistically significant data.

Keywords: Sepsis, vitamin D, mortality.

\section{RESUMO}

Introdução: Atualmente, grande importância tem sido dada ao estudo da Vitamina $C$ na sepse. No entanto, especialmente no contexto de terapia intensiva, há evidências limitadas, mas significativas, da alta prevalência de deficiência de vitamina $D$ em pacientes com sepse e choque séptico, correlacionando-se com a gravidade e probabilidade de disfunção orgânica.

Material e métodos: Estudo retrospectivo, monocêntrico, observacional e descritivo, amostra de conveniência em hospital terciário. Foram analisados 492 pacientes, dos quais 105 tinham diagnóstico de sepse, dos quais 30 tinham dosagem de vitamina $D$. A média de idade foi de 56 anos, predominantemente do sexo masculino (70\%), história de patologia oncológica (26.7\%) e imunossupressão (30\%). Na admissão na unidade de terapia intensiva, 73.3\% estavam em choque, $70 \%$ em ventilação mecânica, com mortalidade média de 16 pontos no APACHE // com mortalidade de $25 \%$ de 8 pontos no SOFA com mortalidade de $15-20 \%$. De acordo com os níveis de vitamina $D$, foram encontrados 2 grupos: Insuficiência (menor que $10 \mathrm{ng} / \mathrm{mL}$ ) e deficiência (maior que $10 \mathrm{n} / \mathrm{mL}$ ).

Resultados: Nenhuma diferença significativa foi encontrada para idade $(p=$ $0.724)$, tempo de internação $(p=0.755)$, SOFA $(p=0.241)$. Há significância estatística no APACHE I/ com escore médio de 19.5 pontos no grupo menor a $10 \mathrm{ng} / \mathrm{mL}$ (mortalidade esperada de 25\%) e de 14.3 pontos no grupo maior a $10 \mathrm{ng} / \mathrm{mL}$ (mortalidade esperada de 15\%). A mortalidade é estimada em $42.9 \%$ no grupo com menor a 10 e 12.5 no grupo maior, mas não é estatisticamente significativa.

Conclusões: Não há correlação com valor estatisticamente significativo entre os níveis de vitamina $D$ e os dias de internação. O percentual de óbito de pacientes com valor menor que $10 \mathrm{ng} / \mathrm{mL}$ sendo $42.9 \%$, ao contrário de pacientes com valor maior que $10 \mathrm{ng} / \mathrm{mL}$ de $12.5 \%$, que não atinge valor estatisticamente significativo, porém a população estudada é pequena, portanto, basta aumentar o tamanho da amostra para obter um valor estatisticamente significativo. Palavras-chave: Sepse, vitamina $D$, mortalidade.

\section{INTRODUCCIÓN}

En la actualidad se ha dado gran importancia a las vitaminas B, C y D. Sin embargo, la vitamina D se ha estudiado en diferentes áreas de especialidades como nefrología, neurología, oncología, reumatología, y en los últimos años en la unidad de cuidados intensivos. Ésta es una prohormona que tiene un papel clave en el equilibrio del calcio, fosfato y la estructura ósea. En la última década, la vitamina $\mathrm{D}$ ha sido objeto de gran interés porque, más allá de los efectos conocidos, los 
datos de estudios observacionales han demostrado relación entre la baja concentración de 25-hidroxivitamina $\mathrm{D}$ en suero con mayor riesgo de cáncer, enfermedades cardiovasculares, trastornos del metabolismo de la glucosa, enfermedades neurodegenerativas y muerte. ${ }^{1}$

A partir del año 2006 en México se ha obtenido información estadística de los niveles de vitamina $D$ en un estudio publicado por ENSANUT. Siendo un primer estudio de acercamiento caracterizando el estado nutricio de la vitamina $D$, en el cual se realizaron mediciones de las concentraciones séricas de 25-OH-D de 964 adultos. Como resultado se encontró que la deficiencia y la insuficiencia de vitamina $D$ son un problema de salud pública en la población mexicana. La concentración de 25-OH-D3 promedio de la población de adultos fue de $28.1 \mathrm{ng} / \mathrm{mL}$. Los resultados mostraron diferencias estadísticamente significativas en las concentraciones séricas de acuerdo con la región ( $p$ menor de 0.05 ). La región norte fue donde se observó la concentración media más elevada $32.3 \mathrm{ng} / \mathrm{mL}$, seguida de la región centro con una media de $28.1 \mathrm{ng} / \mathrm{mL}$. Sin embargo, en la Ciudad de México, se encontró la concentración media más baja $23.2 \mathrm{ng} / \mathrm{mL} .^{2}$

En 2011 el Instituto de Medicina de EUA emitió una publicación que establece una concentración de 25-hidroxivitamina $D$ en suero de $20 \mathrm{ng} / \mathrm{mL}$ como una concentración óptima para la salud ósea de la población norteamericana. En el mismo año, la Sociedad de Endocrinología de EUA recomendó una concentración sérica mínima de $25(\mathrm{OH}) \mathrm{D}$ de $30 \mathrm{ng} / \mathrm{mL}$ para obtener beneficios óptimos para la salud. Al utilizar los valores de la vitamina $D$ establecidos por la Sociedad de Endocrinología de EUA, entre 40 y $100 \%$ de los adultos mayores son insuficientes en vitamina $D$ junto con un estimado de mil millones de personas en el mundo. ${ }^{3,4}$ En México, en el área de cuidados intensivos existe información limitada sobre la relación de vitamina $D$ y sepsis, únicamente hay un estudio realizado por Jiménez y colaboradores en el año 2018, donde se demuestra la elevada prevalencia de la deficiencia de vitamina $D$ en los enfermos con sepsis y choque séptico correlacionándose con la gravedad y la probabilidad de disfunción orgánica. Existe un estudio en la Unidad de Cuidados Intensivos Adultos del Hospital San José Tecnológico de Monterrey realizado por Teijeiro y su equipo en el año 2016, en el que se estableció que los pacientes que ingresan a la unidad de cuidados intensivos en población general cuentan con niveles disminuidos de vitamina $D$; sin embargo, no se correlaciona con severidad o mortalidad, pero sólo ocho pacientes del estudio contaron con diagnóstico de sepsis. ${ }^{5,6}$

Las múltiples funciones de la vitamina $D$ en la respuesta del sistema inmunitario ante una infección sugieren que puede ser un componente integral en la respuesta contra la sepsis. Los datos científicos básicos apuntan hacia el papel de la vitamina $D$ en el funciona- miento óptimo del sistema inmunitario innato, en parte mediante la producción de AMP como LL-37 inhibiendo la cascada inflamatoria inducida por el LPS. Los primeros datos clínicos sobre su papel en la prevención y atenuación de las infecciones han sugerido un vínculo, pero los ensayos de intervención han producido resultados mixtos que requieren mayores estudios como ensayos controlados aleatorizados más amplios para ayudar a definir la relación. Además, los datos clínicos también apuntan hacia el papel de la vitamina $D$ y la enfermedad crítica, pero aún deben determinar una relación directa entre la sepsis, su gravedad y sus resultados. El papel de la vitamina $D$ y su relación con la sepsis es uno de los campos de investigación con mayor interés actualmente en la última década con muchos enlaces importantes que proporcionan un terreno fértil para futuras investigaciones. $^{7}$

La sepsis es una enfermedad común en todos los servicios de medicina interna que en los últimos años ha incrementado su incidencia, sobre todo de severidad y de choque séptico. La epidemiología ha sido evolutiva, a finales del decenio de 1970 ocurrían 164,000 casos en Estados Unidos, para el año 2000 la incidencia aumentó a más de 650,000 casos, quizá como consecuencia de la edad avanzada, inmunosupresión e infecciones por microorganismos resistentes a múltiples fármacos.

En México, Carrillo y colaboradores realizaron un estudio epidemiológico en las unidades de terapia intensiva que reportó una incidencia de 40,957 casos de sepsis al año, lo que indica que hay 40 casos por cada 100,000 habitantes, mientras que la mortalidad es de $30 \%$ y los costos de atención ascienden de 600,000 a $1,870,000$ pesos mexicanos por paciente, lo que muestra la repercusión de la sepsis en nuestro país. ${ }^{8}$

Por tal motivo, es de relevancia poder conocer el estatus de la vitamina $D$ de los pacientes que ingresan a la unidad de terapia intensiva con diagnóstico de sepsis, y también establecer si existe una asociación entre los niveles de vitamina $D$ y la mortalidad, y posteriormente en otro estudio establecer si la suplementación de vitamina $\mathrm{D}$ ofrece beneficio a los pacientes con diagnóstico de sepsis, por lo que es necesario conocer la frecuencia de insuficiencia y deficiencia de vitamina $D$ en nuestra población.

\section{Estructura}

Estructuralmente la vitamina $D$ se deriva de un esteroide y se considera un esteroide seco porque uno de sus cuatro anillos está roto. La vitamina $D$ contiene tres anillos intactos ( $A, C$ y $D$ ) con una ruptura en el anillo B entre los carbonos 9 y 10. Las dos formas principales son la vitamina D2 (también llamada ergocalciferol) y D3 (también llamada colecalciferol), que difieren en la 
estructura de sus cadenas laterales, pero no en su metabolismo general o funciones en el cuerpo. ${ }^{9}$

\section{Fuentes}

La vitamina $\mathrm{D}$ se proporciona como D3 en un número relativamente pequeño de alimentos de origen animal. En los alimentos, la vitamina es bastante estable y, por lo tanto, no es propensa a las pérdidas de cocción, almacenamiento o procesamiento. El contenido de vitamina $D$ de los alimentos se expresa en unidades internacionales (UI) o $\mu \mathrm{g}, 1 \mu \mathrm{g}$ de vitamina $\mathrm{D}=40 \mathrm{UI} \circ$ $1 \mathrm{UI}=0.025 \mu \mathrm{g}$ de vitamina $\mathrm{D}$. Otra fuente importante de vitamina D3 es la que se produce en el cuerpo a partir del esteroide 7-deshidrocolesterol, que se deriva del colesterol. Específicamente, el 7-dehidrocolesterol se produce en las glándulas sebáceas de la piel y se secreta sobre la superficie de la piel, donde se incorpora a las diversas capas de ésta, incluida la dermis y especialmente la epidermis, durante la exposición directa a la luz solar, los fotones ultravioleta B (UVB) (longitud de onda N285 a $320 \mathrm{~nm}$ ) penetran en la epidermis y la dermis, permitiendo que el 7-dehidrocolesterol en las membranas plasmáticas de las células de la piel absorba los fotones, este evento hace que el anillo $B$ se abra formando previtamina D3 (precolecalciferol). Los dobles enlaces inestables en la previtamina D3 se reorganizan (isomerización térmica) durante un periodo de varias horas a unos cuantos días, lo que da como resultado la síntesis de vitamina D3 (colecalciferol). Esta producción cutánea de vitamina D3, que se difunde de la piel a la sangre, representa una fuente clave de la vitamina para muchas personas. Sin embargo, la producción cutánea de la vitamina se ve afectada por la hora del día, la estación, la latitud, la altitud, la capa de nubes, la contaminación del aire, la pigmentación de la piel, el uso de protector solar y la edad. ${ }^{9}$ Los niveles de absorción de vitamina $\mathrm{D}$ se clasifican en: suficiencia $0 \%$, deficiencia $47 \%$ e insuficiencia $53 \%$.

\section{Absorción}

La vitamina D en la dieta (tanto D3 como D2) no requiere digestión y se absorbe de una micela en asociación con la grasa y con la ayuda de la bilis por difusión pasiva en la célula intestinal. Alrededor de $50 \%$ de la vitamina $\mathrm{D}$ en la dieta se absorbe. Aunque la tasa de absorción es más rápida en el duodeno y el yeyuno proximal, la mayor cantidad de vitamina $D$ se absorbe en el yeyuno. La ausencia de yeyuno (secundaria a resección quirúrgica) se ha asociado con una probabilidad cinco veces mayor de deficiencia de vitamina $D$. Dentro de las células intestinales, la vitamina $D$ se incorpora principalmente a los quilomicrones, que luego ingresan en el sistema linfático y posteriormente en la sangre.
Al igual que con la vitamina $\mathrm{A}$, las condiciones asociadas con la mala absorción de la grasa tienen un impacto negativo en la absorción intestinal de la vitamina $\mathrm{D} .^{9}$

Transporte, metabolismo y almacenamiento. Los quilomicrones transportan la vitamina $\mathrm{D}$ que proviene de la dieta a los tejidos no hepáticos en todo el cuerpo. Los remanentes de quilomicrones envían la vitamina al hígado, que retiene los remanentes por endocitosis. En contraste con la vitamina D obtenida por los alimentos, la vitamina D3 que se produce en la piel se difunde lentamente de la piel y para su transporte en la sangre es recogida por una proteína de unión a la vitamina D (DBP).

La vitamina $D$ que llega al hígado, ya sea por medio de remanentes de quilomicrones o por DBP, debe ser hidroxilada por las hidroxilasas del citocromo P-450 para comenzar la generación de la forma activa de la vitamina D. En el hígado, la 25-hidroxilasa (principalmente CYPZAI), que es dependiente de NADPH, funciona en las mitocondrias para hidroxilar vitamina D3 en el carbono 25 para formar $25-\mathrm{OH}$ (vitamina) D, también llamada calcidiol o 25-OH colecalciferol. Otra 25-hidroxilasa (CYP2R1) encontrada en los microsomas también hidroxila la D3 y D2. Mientras que el hígado expresa la mayoría de las 25-hidroxilasas, la enzima se encuentra en otros órganos, incluidos los pulmones, el intestino y los riñones. Si bien la enzima no está regulada en gran medida, la 25-hidroxilasa es más eficiente durante los periodos de privación de vitamina $D$ que cuando están disponibles cantidades normales de la vitamina. Después de su síntesis hepática, la mayoría del 25-OH D se secreta desde el hígado y se transporta en la sangre por DBP. La sangre es el grupo más grande y representa el sitio de almacenamiento principal de la vitamina como 25-OH D, que tiene una vida media de aproximadamente dos a tres semanas o más. La vitamina $D$ también se almacena en el tejido adiposo, que contiene principalmente vitamina $D$ no hidroxilada y músculo, que contiene tanto vitamina $\mathrm{D}$ como $25-\mathrm{OH} \mathrm{D}$.

El 25-OH D es absorbido por los tejidos (principalmente por los riñones) en respuesta al aumento de las concentraciones de la hormona paratiroidea $(\mathrm{PTH})$.

Específicamente, el complejo 25-OH D-DBP se une a un sistema receptor de membrana de megalina cubulina en la membrana plasmática de las células del túbulo proximal de los riñones para formar un complejo megalina-DBP-25-OHD. El complejo se internaliza por endocitosis en las células, donde se libera el 25-OH D y luego se hidroxila en la posición 1 para establecer la forma activa de la vitamina, 1,25- $(\mathrm{OH}) 2$ (vitamina) D (también Ilamada calcitriol o 1,25 dihidroxicolecalciferol). La 1-hidroxilasa (CYP27B1), una enzima mitocondrial dependiente de NADPH, se expresa en las concentraciones más altas en los riñones, pero también está presente en macrófagos, piel, intestino y hueso, entre otros tejidos. Gran parte del calcitriol que se produce en los riñones 
se libera finalmente en la sangre para que otros tejidos lo utilicen. La síntesis renal de calcitriol está estrechamente regulada por dos hormonas, la PTH y el factor de crecimiento de tipo fibroblasto.

El calcitriol, que se produce en los riñones, se libera en la sangre donde se une a la DBP para su transporte. Por lo tanto, la DBP sirve para transportar varias formas de la vitamina a diversos tejidos diana. Sin embargo, la unión de DBP al calcitriol es débil para facilitar la liberación de la vitamina a los tejidos; esto contrasta con su unión estrecha de 25-OH D. El calcitriol en la sangre tiene una vida media de aproximadamente de dos a seis horas; las concentraciones plasmáticas normales de calcitriol varían aproximadamente de 20 a 40 pg/mL, considerablemente más bajas que las concentraciones plasmáticas de 25-OHD. Al alcanzar sus tejidos diana, el calcitriol se libera fácilmente de la DBP para captación celular. Se creía que los tejidos diana del calcitriol se limitaban inicialmente al intestino, los huesos y los riñones, pero ahora se sabe que los receptores de la vitamina se encuentran en muchos tejidos, incluyendo el corazón, el músculo, el páncreas (células B), el cerebro, piel, colon, próstata, mama, sistema hematopoyético, sistema nervioso central y sistema inmunológico (Figura 1). ${ }^{9}$

\section{Niveles séricos de vitamina D}

En 2011 el Instituto de Medicina de EUA emitió una publicación que establece una concentración de 25-hidroxivitamina $D$ sérica de $20 \mathrm{ng} / \mathrm{mL}$ como una concentración óptima para la salud ósea de la población norteamericana. En el mismo año, la Sociedad de Endocrinología de EUA recomendó una concentración sérica mínima de $25(\mathrm{OH}) \mathrm{D}$ de $30 \mathrm{ng} / \mathrm{mL}$ para obtener beneficios óptimos para la salud. ${ }^{3,10}$

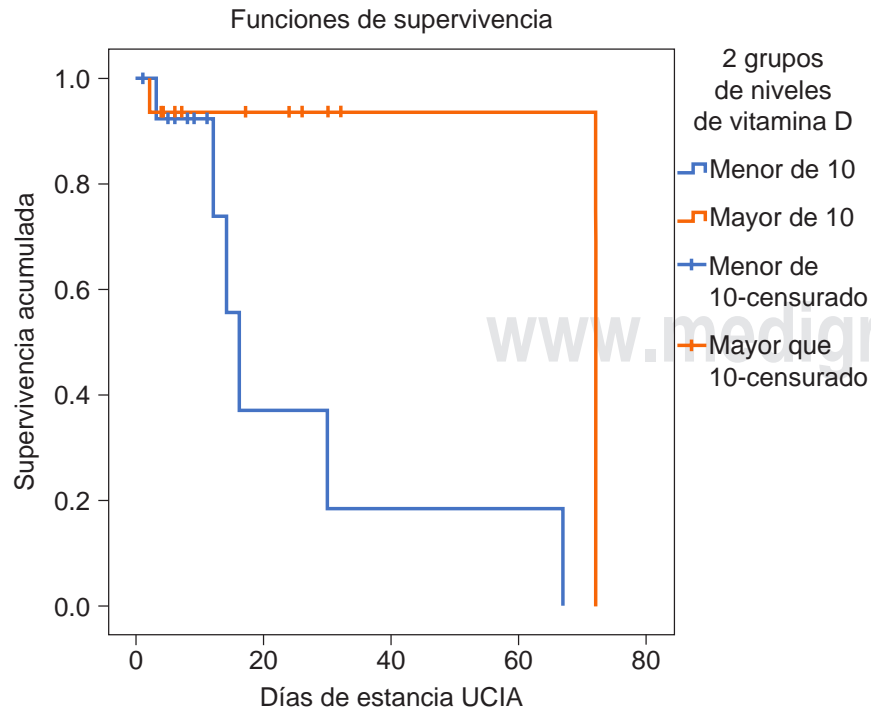

Figura 1: Supervivencia por agrupación según niveles de vitamina D.
$Y$ se define insuficiencia de vitamina $D$ al obtener un valor sérico de 10 a $29 \mathrm{ng} / \mathrm{mL}$, y deficiencia con un valor de $9 \mathrm{ng} / \mathrm{mL}$ o menor. ${ }^{3,4}$

\section{Deficiencia de vitamina D}

El nivel de 25-hidroxivitamina $D$ en suero es el mejor indicador del estado general de vitamina $D$ porque esta medida refleja la vitamina $D$ total de la ingesta dietética, la exposición a la luz solar y la conversión de vitamina $\mathrm{D}$ de las reservas de tejido adiposo en el hígado. La Encuesta Nacional de Evaluación de la Salud y la Nutrición (NHANES) en los Estados Unidos estableció que la ingesta dietética promedio de vitamina $D$ (incluidos los suplementos) puede ser baja, hasta de 200 UI por día (con diferencias según la edad). ${ }^{11}$

La síntesis de vitamina $D$ es bastante variable, dependiendo de la pigmentación, latitud, estación, vestimenta, edad, uso de protector solar y condiciones climáticas locales. Los niveles de 25-hidroxivitamina $D$ son considerablemente más bajos entre la raza negra que entre la raza caucásica debido a la mayor pigmentación en la primera. En caucásicos sanos los niveles séricos de 25 -hidroxivitamina $D$ pueden variar según los factores ambientales, hormonales, genéticos y nutricionales. El índice de masa corporal (IMC), por ejemplo, está inversamente relacionado con el suero. El nivel de 25-hidroxivitamina $D$ y los pacientes obesos suelen tener niveles en el rango de 10 a 20 ng por mililitro; estas diferencias pueden deberse en parte a los niveles más bajos de ejercicio y exposición a la luz solar en personas obesas que en personas delgadas. Varias condiciones causan niveles séricos muy bajos de 25-hidroxivitamina $D$ (es decir, por debajo de $10 \mathrm{ng}$ por mililitro), incluida una ingesta dietética deficiente de vitamina $\mathrm{D}$ junto con una exposición mínima al sol; malabsorción debido a enfermedad inflamatoria intestinal, enteropatía por gluten, cirugía gástrica, enfermedad biliar o sobrecrecimiento intestinal, uso de medicamentos anticonvulsivos (por ejemplo, fenobarbital o fenitoína) y el uso a largo plazo de glucocorticoides. ${ }^{11}$

Definir un nivel de 25-hidroxivitamina $D$ en suero como bajo o insuficiente depende del nivel que se define como normal. Anteriormente, según la Organización Mundial de la Salud, los niveles por debajo de $10 \mathrm{ng}$ por mililitro se consideraban deficientes y los niveles por debajo de 20 ng por mililitro se clasificaban como insuficientes. Sin embargo, con los cambios recientes en los rangos de referencia de laboratorio, un nivel normal se define actualmente como un nivel sérico de 30 a $76 \mathrm{ng}$ por mililitro. Cuando se utiliza ese rango, la prevalencia estimada de la insuficiencia de vitamina $\mathrm{D}$ es de 50 a $80 \%$ en la población general.

Según la NHANES de 2005 y 2006, el nivel medio de 25 -hidroxivitamina $D$ en varios grupos de edad era 24 
ng por mililitro, un nivel considerado insuficiente según algunos estándares.

Existen dos razones para establecer el límite inferior del rango normal de 25-hidroxivitamina $D$ a $30 \mathrm{ng}$ por mililitro: estudios publicados en los últimos años sugieren que los niveles de hormona paratiroidea (PTH) aumentan cuando los niveles de la 25-hidroxivitamina D caen por debajo de $30 \mathrm{ng}$ por mililitro; el otro, propuesto en estudios anteriores, sugiere que la absorción activa de calcio es óptima cuando el nivel de 25-hidroxivitamina $D$ es 30 ng por mililitro. En general, la absorción máxima de calcio se produce a niveles entre 20 y $30 \mathrm{ng}$ por mililitro. ${ }^{11}$

Algunos datos de otros países sugieren que la incidencia de niveles bajos de 25-OHD en los ancianos es más común de lo que se pensaba, alcanzando $80 \%$ en mujeres de 80 años que viven en hogares de ancianos en los Países Bajos. Incluso en adolescentes, la deficiencia/insuficiencia de vitamina D puede alcanzar $42 \%$ utilizando un punto de corte de $20 \mathrm{ng} / \mathrm{mL}$ para el suero 25-OHD. ${ }^{12,13}$

En Sídney, Australia, un estudio realizado en hombres mayores de 60 años, donde se incluyeron 41 con fracturas del cuello femoral, 41 hospitalizados por otros motivos y 41 ambulatorios, reveló que los niveles séricos medios de 25-OHD eran significativamente más bajos en los pacientes con fracturas del cuello femoral $18.2 \mathrm{ng} / \mathrm{mL}$ que en los pacientes hospitalizados por otras razones $24.4 \mathrm{ng} / \mathrm{mL}$ o en pacientes ambulatorios $25.4 \mathrm{ng} / \mathrm{mL}$. La deficiencia subclínica de vitamina $\mathrm{D}$ (definida aquí como un nivel de $25-\mathrm{OHD}$ en suero por debajo de $20 \mathrm{ng} / \mathrm{mL}$ ) ocurrió en $63 \%$ de los pacientes con fracturas del cuello femoral, en comparación con $25 \%$ de los pacientes ambulatorios (razón de probabilidades = 3.9; IC = 1.74-8.78; $p=0.0007$ ). Cuando se analizó en relación con otros factores de riesgo de osteoporosis como la edad, el peso corporal, las afecciones mórbidas concomitantes, el consumo de alcohol, el hábito de fumar y el uso de corticoides, la deficiencia subclínica de vitamina $D$ fue el factor más importante para predecir el riesgo de fracturas del cuello femoral. ${ }^{14}$

\section{Estatus de la vitamina D en México}

Para conocer el estado de vitamina $D$ en niños, adolescentes y adultos en México se desarrolló un estudio sobre una submuestra representativa de niños, adolescentes y adultos de México con datos de la ENSANUT 2006. En total se midieron las concentraciones séricas de 25-OH-D en suero de 1,025 niños, 513 adolescentes y 964 adultos. Los resultados mostraron que la deficiencia y la insuficiencia de vitamina $\mathrm{D}$ son un problema de salud pública en población mexicana. Este estudio es uno de los primeros a nivel mundial que documenta concentraciones séricas y prevalencias de deficiencia de vitamina $D$ en una muestra poblacional de representatividad nacional y el primer estudio de vitamina $D$ representativo a nivel nacional en México. Se midieron las concentraciones séricas de 25-OH-D en suero por medio de ELISA directo en una muestra representativa nacional. Se aplicaron factores de expansión, de modo que los resultados son extrapolables a 8,000,000 niños, 504,000 adolescentes y 1,080,000 adultos mexicanos.

La muestra de los adultos mexicanos comprendió un total de 964 personas mayores de 20 años de edad que son representativas de alrededor de 1,000,000 de adultos mexicanos. La concentración promedio de vitamina $D$ de los adultos del estudio fue de $39 \mathrm{ng} / \mathrm{mL}$. Los resultados mostraron diferencias estadísticamente significativas en las concentraciones séricas de acuerdo con la región $(p<0.05)$. La región norte fue donde se observó la concentración media más elevada (44.5 ng/ $\mathrm{mL}$ ), seguida de la región centro con una media de 97.5 nmol/L. Sin embargo, en la Ciudad de México se encontró la concentración media más baja $32 \mathrm{ng} / \mathrm{mL}$.

No obstante, fue en este mismo grupo donde no se detectó ningún caso de deficiencia severa $(<8 \mathrm{ng} / \mathrm{mL})$ o de insuficiencia. En contraste, fue en el grupo de adultos con peso normal donde encontramos la mayor prevalencia de deficiencia (25-OH-D3 < $20 \mathrm{ng} / \mathrm{mL}) 10.9 \%(p=0.8)$.

Los adultos entre 50 y 59 años de edad presentaron una prevalencia de deficiencia o insuficiencia de $22 \%$, en comparación con las personas entre 30 y 49 años de edad donde se encontró una prevalencia de alrededor de $33 \%$. En los adultos con obesidad se detectó la mayor prevalencia de deficiencia o insuficiencia cercana a $32 \%$, contrastando con los adultos con IMC bajo en quienes se observó una prevalencia de alrededor de $6 \%$. De acuerdo con el área de residencia se detectó la menor prevalencia de deficiencia o insuficiencia en el área rural (26.4\%). Respecto a las regiones, predominó la región de la Cuidad de México con una prevalencia ligeramente menor de $45 \%$ con concentraciones de vitamina $D<30 \mathrm{ng} / \mathrm{mL}$. Igualmente respecto al nivel socioeconómico, fue en el nivel medio donde los resultados mostraron la prevalencia más elevada de esta deficiencia nutricional con una prevalencia de casi $36 \% .^{2}$

Ochoa y colaboradores en el periodo comprendido entre 2013 y 2014 realizaron un estudio en población mexicana en Monterrey, Nuevo León, México para establecer la prevalencia de la deficiencia de vitamina $D$ en madres y sus neonatos, y analizar factores de riesgo asociados. Se incluyeron 191 puérperas y sus neonatos de término. Se analizaron las concentraciones séricas de 25 hidroxi-vitamina $D$ y se correlacionaron con factores de riesgo maternos y datos antropométricos neonatales. Se presentó deficiencia en $61 \%$ de las madres y en $26 \%$ insuficiencia. De los neonatos, $98 \%$ mostraron deficiencia (66\% grave). Existe una correlación positiva 
entre las concentraciones de vitamina $D$ de madres $y$ neonatos ( $r 2=0.173 ; p=0.017$ ). Los valores más bajos se presentaron en otoño (15.75 y $6 \mathrm{ng} / \mathrm{mL}$ materna y neonatal, respectivamente). No hubo correlación entre los valores de vitamina D materna y su alimentación, fototipo, tiempo de exposición solar o índice de masa corporal. ${ }^{15}$

\section{Vitamina D y cuidados intensivos}

La deficiencia de vitamina $D$ es común en enfermedades críticas con prevalencia entre 40 y $70 \%$. En pacientes quemados, la prevalencia parece ser aún mayor. Muchos pacientes ingresan a la $\mathrm{UCl}$ en un estado deficiente debido a malnutrición y enfermedad preexistentes. Sin embargo, el metabolismo de la vitamina $D$ está desregulado en algunos pacientes críticamente enfermos con niveles de vitamina $D$ que caen de manera rápida después del ingreso en la UCI. La similitud entre los resultados en diversas áreas geográficas con exposición variable a UVB sugiere que la influencia de la enfermedad crónica y/o aguda individual sobre la deficiencia de vitamina $D$ es en gran medida independiente de la exposición al sol. Varios estudios grandes observacionales en todo el mundo han confirmado que la deficiencia de vitamina D (generalmente definida como niveles de $25(\mathrm{OH}) \mathrm{D}$ por debajo de $20 \mathrm{ng} / \mathrm{mL}$ ) es frecuente en enfermedades críticas pediátricas y de adultos. Se ha demostrado que la deficiencia de vitamina $D$ está asociada con sepsis, síndrome de dificultad respiratoria aguda y lesión renal aguda, y tres metaanálisis diferentes confirman que los pacientes con un estado bajo de vitamina $\mathrm{D}$ tienen una estadía en la UCI más prolongada y mayor morbilidad y mortalidad.

Recientemente, se encontraron diferencias metabólicas importantes en las vías relacionadas con el metabolismo del glutation y el metabolismo del glutamato en un estudio observacional en deficiencia de vitamina $\mathrm{D}$ en comparación con pacientes no deficientes en $\mathrm{UCI}$ (separados por un corte de $15 \mathrm{ng} / \mathrm{mL}$ ) ${ }^{13,16-20}$

En enfermedades críticas también hay evidencia de caídas rápidas en las concentraciones circulantes de $25(\mathrm{OH}) \mathrm{D}$, posiblemente debido a un metabolismo interrumpido, reanimación con líquidos, disminución de la síntesis de la proteína de unión a la vitamina $\mathrm{D}$ debido a disfunción hepática, extravasación intersticial causada por el aumento de la permeabilidad vascular, pérdida renal de vitamina $D$, disminución de la conversión renal a 1,25 (OH) D3 y aumento de la conversión tisular de $25(\mathrm{OH})$ D3 a 1,25 (OH) D3. El papel de la vitamina D libre/biodisponible sigue sin estar claro, aunque es posible que aunque la proteína de unión a la vitamina D (VDBP), y por lo tanto la $D$ total disminuya, la $D$ libre circulante pueda mantenerse. ${ }^{21}$
En un análisis post hoc del ensayo VITDAL-UCI, la vitamina $\mathrm{D}$ libre/biodisponible no fue superior al total de $25(\mathrm{OH}) \mathrm{D}$ en la predicción de la mortalidad ni en el placebo, ni en el grupo de intervención. También hay evidencia de que los pacientes críticamente enfermos con concentraciones muy bajas de $25(\mathrm{OH}) \mathrm{D}$ tienen respuestas contundentes al reemplazo de vitamina $D$, posiblemente debido a la conversión en metabolitos alternativos y epiformes. ${ }^{17}$

\section{Vitamina D y su relación con en el sistema inmunitario}

Las acciones inmunomoduladoras de la vitamina $D$ han sido reconocidas por más de un cuarto de siglo, la mayor conciencia de los bajos niveles circulantes de precursor de 25-hidroxivitamina $D$ en poblaciones de todo el mundo ha llevado a investigaciones epidemiológicas de problemas de salud asociados con la insuficiencia de vitamina D. Entre estos problemas destacan las enfermedades autoinmunes como la esclerosis múltiple, la diabetes tipo 1 y la enfermedad de Crohn, pero estudios más recientes indican que las infecciones como la tuberculosis también pueden estar relacionadas con niveles bajos de 25-hidroxivitamina D. El segundo factor que expande el vínculo entre la vitamina $D$ y el sistema inmunológico es nuestro mejor conocimiento de los mecanismos que facilitan esta asociación. Ahora está claro que las células del sistema inmunológico contienen toda la maquinaria necesaria para convertir 25-hidroxivitamina $D$ en 1,25-dihidroxivitamina $D$ activa, y para las respuestas posteriores a 1,25-dihidroxivitamina $D$.

Los mecanismos como éste son importantes para promover respuestas antimicrobianas a patógenos en macrófagos, y para regular la maduración de células dendríticas presentadoras de antígeno. ${ }^{22}$

La vitamina $D$ tiene numerosos efectos en las células dentro del sistema inmunológico. Inhibe la proliferación de células $B$ y bloquea la diferenciación de células $B$ y la secreción de inmunoglobulina. La vitamina $D$ además suprime la proliferación de células $\mathrm{T}$ y da como resultado un cambio de un fenotipo TH1 a uno TH2. Además, afecta la maduración de las células T con un sesgo lejos del fenotipo inflamatorio TH17 y facilita la inducción de las células reguladoras $T$. Estos efectos resultan en una disminución en la producción de citoquinas inflamatorias (IL-17 e IL-21) con un aumento de la producción de citoquinas antiinflamatorias como la IL-10. La vitamina D también tiene efectos en los monocitos y las CD. Inhibe la producción de monocitos de citoquinas inflamatorias, tales como IL-1, IL-6, IL-8, IL-12 y TNF. Además, inhibe la diferenciación y maduración de DC con la preservación de un fenotipo inmaduro como lo demuestra la disminución de la expresión de las moléculas MHC de clase II, las moléculas coestimuladoras y la IL12.22,23 


\section{Vitamina D y su relación con la sepsis}

Destacando la importancia de los descubrimientos recientes de los efectos pleiotrópicos de la vitamina $D$ en la salud humana, numerosas publicaciones recientes han explorado la definición de deficiencia de vitamina D y su prevalencia. La ciencia ha comenzado a revelar posibles vínculos entre su deficiencia y la sepsis. Un papel vital para la vitamina $D$ en el sistema humano fue resaltado inicialmente por el descubrimiento de receptores de vitamina D (VDR) en casi todos los tipos de células inmunitarias, incluidas las células T CD4 + y CD8 + activadas, células B, neutrófilos, macrófagos y células dendríticas. Estas células abarcan las respuestas inmunitarias innatas y adaptativas del cuerpo a los patógenos. La relación descubierta por los científicos es compleja, pero el tema subyacente parece ser el de la modulación de la respuesta inmunitaria adaptativa al tiempo que promueve la inmunidad innata. En cuanto a la inmunidad adaptativa, la vitamina $D$ afecta la proliferación y diferenciación de las células $\mathrm{B}$ y $\mathrm{T}$, además de modular la producción de inmunoglobulina. ${ }^{22,24}$

El sistema inmunitario innato actúa para identificar rápidamente los organismos invasores y responder con mecanismos de defensa humoral y celular para contener, neutralizar y eliminar los patógenos ofensivos. Estos patógenos se identifican mediante patrones moleculares asociados a patógenos altamente conservados (PAMP) que se unen a los receptores de reconocimiento de patógenos (PRR) en las células inmunes. Las células que participan en estas respuestas inmunitarias innatas incluyen neutrófilos y monocitos así como células epiteliales que no sólo proporcionan una función de barrera, sino que también tienen actividad antipatógena. La vitamina $D$ es un componente clave en varias de las vías de este sistema. ${ }^{22}$

Los monocitos desempeñan funciones importantes en el sistema inmunitario innato como células presentadoras de antígenos así como en la fagocitosis. Los monocitos humanos reconocen algunos PAMP por una familia de moléculas transmembrana, los receptores tipo Toll (TLR), como TLR4, reconocen específicamente y se unen al lipopolisacárido (LPS), una sustancia producida por bacterias gramnegativas y un potente estimulador de la cascada inflamatoria de sepsis. Sadeghi y colaboradores demostraron que los monocitos humanos estimulados con LPS y tratados con 1,25-dihidroxivitamina $\mathrm{D}(1,25(\mathrm{OH}) 2 \mathrm{D})$ mostraron disminuciones dependientes de la dosis en la síntesis de TLR2 y TLR4 con un aumento en CD14, una molécula coestimuladora de TLR. Además, encontraron que 1,25 $(\mathrm{OH}) 2 \mathrm{D}$ disminuía el TNFa y el factor tisular, ambos productos finales de la activación de LPS e importantes moléculas inflamatorias en la sepsis. Estos efectos se revirtieron con la introducción de un antagonista VDR, lo que re- fuerza un papel clave de la vitamina $D$ en este mecanismo de señalización. Otros estudios han revelado un papel de la vitamina $D$ en la respuesta endotelial al LPS. En la sepsis, el LPS activa las células endoteliales para producir el factor de transcripción NFkB, las citoquinas proinflamatorias IL-6 e IL-8, y la quimiocina, RANTES. En un estudio realizado por Equils y su equipo las células endoteliales humanas tratadas con 1,25 (OH) 2D y luego estimuladas con LPS mostraron una inhibición significativa de estas moléculas cuando se compararon sólo con las células expuestas al LPS. Estos hallazgos pueden sugerir que la vitamina $D$ actúa para modular la respuesta endotelial proinflamatoria al LPS. ${ }^{25}$

Durante las últimas dos décadas, estas intrigantes respuestas celulares dependientes de la vitamina $D$ al LPS también se han estudiado en modelos de sepsis en ratas y ratones. Horiuchi y colaboradores estudiaron ratones expuestos simultáneamente a LPS intraperitoneal y 1,25 (OH) 2D oral. En comparación con los controles, los ratones que recibieron vitamina $D$ tenían menos expresión de la molécula inflamatoria iTXB2, y una disminución en la mortalidad. En 2001 Asakura y colegas demostraron que en comparación con la heparina de bajo peso molecular, el tratamiento con 1,25 $(\mathrm{OH}) 2 \mathrm{D}$ oral tuvo efectos iguales o mejorados en los parámetros hemostáticos y marcadores de disfunción orgánica en ratas infundidas con LPS. En 2007 Moller y colaboradores realizaron ensayos controlados con placebo del tratamiento con 1,25 $(\mathrm{OH}) 2 \mathrm{D}$ en tres modelos diferentes de sepsis en ratas que mostraron resultados variados. Si bien los diferentes modelos de tratamientos de sepsis y vitamina $D$ en estos experimentos hacen que sean difíciles de comparar, cuando se combinan con los datos in vitro sugieren que la vitamina $D$ tiene importantes efectos moduladores en la respuesta inmunitaria innata a la sepsis inducida por LPS. ${ }^{25}$

Parekh y su equipo reclutaron 61 pacientes con sepsis y sepsis grave de dos grandes hospitales del Reino Unido y 20 controles sanos. Se llevaron a cabo modelos murinos de ligadura y punción cecal y lipopolisacáridos intratraqueal en ratones normales y deficientes de vitamina D para abordar el problema de la causalidad. Los pacientes con sepsis grave tuvieron concentraciones significativamente más bajas de 25-hidroxivitamina D3 que los pacientes con sepsis leve o controles sanos de la misma edad (15.7 vs. 49.5 vs. $66.5 \mathrm{nmol} / \mathrm{L} ; \mathrm{p}$ $=0.0001)$. Las concentraciones de 25-hidroxivitamina D3 fueron significativamente más bajas en los pacientes que tuvieron un cultivo microbiológico positivo que en los que tuvieron un cultivo negativo ( $p=0.0023)$ así como en los que fallecieron dentro de los 30 días de la admisión al hospital $(p=0.025)$. La deficiencia de vitamina $D$ en la sepsis murina se asoció con un aumento del cultivo bacteriano cuantitativo peritoneal $(p$ $=0.037)$, sistémico $(p=0.019)$ y lavado broncoalveo- 
lar $(p=0.011)$. Esto se asoció con una expresión local reducida del péptido antimicrobiano relacionado con la catelicidina así como con evidencia de fagocitosis macrófaga defectuosa $(p=0.029)$. En el modelo de lipopolisacáridos intratraqueal, 1,500 UI de colecalciferol intraperitoneal en el tratamiento seis horas después de la lesión redujeron la inflamación alveolar, el daño celular y la hipoxia. La deficiencia de vitamina $D$ es común en la sepsis grave. Esto parece contribuir al desarrollo de la condición en los modelos murinos clínicamente relevantes y se deben desarrollar enfoques para corregir la deficiencia de vitamina $D$ en pacientes con sepsis. ${ }^{25}$

Moromizato y colaboradores realizaron un estudio con la hipótesis de que la deficiencia de 25-hidroxivitamina $D$ antes del ingreso hospitalario se asociaría con sepsis en los pacientes críticos. En un estudio observacional en dos centros de pacientes tratados en $\mathrm{UCI}$ médicas y quirúrgicas con 209 camas médicas y quirúrgicas de cuidados intensivos en dos hospitales de enseñanza en Boston, MA se obtuvo una muestra total de 3,386 pacientes mayores de 18 años, en los que se midió la 25-hidroxivitamina $\mathrm{D}$ antes de la hospitalización entre 1998 y 2011. Sin aplicar intervención, la admisión previa a 25-hidroxivitamina $\mathrm{D}$ se clasificó como deficiencia en 25-hidroxivitamina $D(\leq 15 \mathrm{ng} / \mathrm{mL})$, insuficiencia $(15-30 \mathrm{ng} / \mathrm{mL})$ y suficiencia $(\geq 30 \mathrm{ng} / \mathrm{mL})$. La deficiencia de 25 -hidroxivitamina $D$ previa a la transmisión predice el riesgo de sepsis. En la cohorte completa, la deficiencia de 25-hidroxivitamina $\mathrm{D}$ es un predictor significativo de riesgo de Clasificación Internacional de Enfermedades, $9^{a}$ edición, sepsis definida por modificación clínica luego de un ajuste multivariable que incluye edad, género, raza, tipo (quirúrgico vs. médico) e Índice de Deyo-Charlson (Odds Ratio ajustado, 1.51 [IC 95\%, 1.17-1.94]; $p=0.001$ ) en relación con pacientes con suficiencia de 25 -hidroxivitamina D. En un subgrupo de pacientes de cohortes enriquecidas se colocaron aquéllos con Clasificación Internacional de Enfermedades, 9a edición.

Modificación clínica: sepsis diagnosticada $(n=444)$, la deficiencia previa a la admisión de 25-hidroxivitamina $\mathrm{D}$ es un factor predictivo significativo de riesgo de sepsis definida en las pautas de la conferencia después de un ajuste multivariado que incluye edad, sexo, raza, tipo (quirúrgico versus médico) y fisiología aguda y evaluación de salud crónica II (Odds Ratio ajustado, 2.05 [IC $95 \%, 1.19-3.52] ; p=0.009)$ en relación con los pacientes con suficiencia de 25-hidroxivitamina D. Además, en pacientes de cohorte con Clasificación Internacional de Enfermedades, $9^{a}$ edición, sepsis definida por modificación clínica ( $n=568$ ), el riesgo multivariado ajustado de mortalidad a los 90 días fue 1.6 veces mayor en aquéllos con valores de preadmisión 25-hidroxivitamina $\mathrm{D}$ en el rango insuficiente y deficiente, en comparación con aquéllos con insuficiencia de vitamina $D$ previa a la admisión (Odds Ratio ajustado, 1.63 [IC 95\%, 1.112.39]; $p=0.01){ }^{26}$

Majid y colaboradores realizaron un estudio transversal en pacientes mayores de 18 años sospechosos de sepsis, que se presentaron a un servicio de urgencias durante un año utilizando muestras de conveniencia no probabilística. A todos los pacientes elegibles se extrajo una muestra de sangre para medir el nivel sérico de vitamina D3 y se evaluó la correlación de esta vitamina con resultados tales como mortalidad, insuficiencia renal, insuficiencia hepática, etc. Se estudiaron 168 pacientes con una edad media de $70.8 \pm 13.3$ (43.093.0) años (56.0\% hombres). El nivel sérico medio de vitamina D3 en los pacientes estudiados fue de $19.03 \pm$ $13.08(4.0-85.0) \mathrm{ng} / \mathrm{mL}$. Al considerar de 20 a $50 \mathrm{ng} / \mathrm{mL}$ como el rango normal de vitamina $\mathrm{D}, 61.6 \%$ de los pacientes tenía deficiencia de vitamina D. Sólo la edad $(r=$ $-0.261, p=0.037)$ y la mortalidad $(r=-0.426, p=0.025)$ mostraron una correlación significativa con la media de vitamina $\mathrm{D}$. Los pacientes con sepsis de mayor edad y los que murieron tenían un nivel más bajo de vitamina D. El área bajo la curva ROC del nivel de vitamina D en suero con respecto a la mortalidad a un mes de los pacientes con sepsis fue de 0.701 (IC de 95\%: 0.4390.964). La prevalencia de deficiencia de vitamina $D$ en pacientes con sepsis que se presentaron en el servicio de urgencias se estimó en $61.6 \%$. Se encontró una correlación significativa e indirecta entre el nivel sérico de vitamina D3 y la mortalidad así como la edad avanzada. Por lo que se concluye que el consumo de suplementos de vitamina $\mathrm{D}$ podría ser útil para disminuir la prevalencia de infección, sepsis y mortalidad causada por ésta, especialmente en la edad avanzada. ${ }^{27}$ Yaghoobi y colaboradores investigaron la asociación entre el nivel de vitamina $D$ en suero y la gravedad y el pronóstico de la neumonía asociada a ventilador (VAP) en pacientes hospitalizados en unidades de cuidados intensivos (UCI). Se incluyeron 84 pacientes consecutivos con VAP en este estudio prospectivo observacional realizado en la UCl del Hospital de Besat, Hamadan. Los pacientes fueron examinados para determinar el nivel de 25-hidroxivitamina $D$ en suero y la severidad y pronóstico de la VAP. La puntuación clínica de infección pulmonar se utilizó para el diagnóstico y la evaluación de la falla secuencial de los órganos (SOFA) para determinar la gravedad de la VAP. Se encontró un bajo nivel de vitamina D3 en suero (menos de $30 \mathrm{ng} / \mathrm{mL}$ ) en 66 pacientes $(78.6 \%)$. En esta serie de pacientes con VAP no hubo diferencias significativas en los resultados del hemocultivo, la mortalidad asociada a sepsis de 14 y 28 días, la duración de la ventilación mecánica o la puntuación SOFA en los días tres, siete y 14 entre el nivel bajo y el nivel normal de vitamina D3 en pacientes ( $p$ $>0.05$ ), por lo que el nivel sérico de vitamina D3 no se asoció con la mortalidad por VAP o con las complicacio- 
nes debidas a la sepsis en los pacientes hospitalizados en la UCl. ${ }^{28}$

Ratzinger y su equipo establecieron que el papel clínico de la vitamina $D$ en la sepsis y la predicción de la mortalidad se discute controversialmente. Por tal motivo, se realizó un estudio de cohorte prospectivo en salas de atención estándar que incluyó a 461 pacientes con sospecha de sepsis que cumplían con dos o más criterios SIRS. En el primer y tercer día después del inicio de los síntomas de SIRS se analizaron los niveles de $25(\mathrm{OH}) \mathrm{D}, 1,25(\mathrm{OH}) \mathrm{D}$ y biomarcadores de sepsis para determinar su capacidad predictiva para identificar infecciones, bacteriemia y riesgo elevado de mortalidad. Además, se evaluaron varios polimorfismos de un solo nucleótido asociados con el metabolismo de la vitamina D. Los pacientes bacterémicos $(28.5 \%)$ presentaron niveles de 1,25 $(\mathrm{OH}) \mathrm{D}$ significativamente más bajos que los pacientes con SIRS sin bacteriemia el primer y tercer día, mientras que $25(\mathrm{OH}) \mathrm{D}$ no mostraron una capacidad predictiva. No se encontraron diferencias significativas de los niveles de 1,25 (OH) D o $25(\mathrm{OH})$ $D$ entre los pacientes con SIRS con y sin infecciones o entre los sobrevivientes y los no sobrevivientes. Los biomarcadores de sepsis que incluyen la procalcitonina y la PCR mostraron una capacidad discriminatoria significativamente mayor para estas tareas de clasificación. Los SNP relacionados con el metabolismo de la vitamina $D$ analizados no indicaron ninguna asociación con las medidas de resultado. En conclusión, 1,25 (OH) D, pero no $25(\mathrm{OH}) \mathrm{D}$, mostró un valor discriminatorio menor para la predicción de bacteriemia que fue inferior a la PCR y la PCT, pero ninguno pudo predecir la sepsis y la mortalidad en una cohorte prospectiva de pacientes con SIRS. ${ }^{29}$

Jiménez y colaboradores evaluaron la prevalencia de la deficiencia de 25-hidroxivitamina $D(25(\mathrm{OH}) \mathrm{D})$ en el servicio de medicina interna y sus consecuencias en escalas de gravedad, falla orgánica y días de estancia intrahospitalaria.

Realizaron un estudio prospectivo, observacional y analítico. Se incluyó un total de 60 pacientes que cumplieran con criterios de sepsis de acuerdo con la última definición (sepsis-3), los cuales fueron sometidos a dos determinaciones de niveles séricos de 25(OH)D (primera medición a ingreso y segunda a egreso). De la muestra, $81.7 \%$ (49 pacientes) presentó deficiencia de $25(\mathrm{OH}) \mathrm{D}$, insuficiencia de 16.7\% (10 pacientes) y sólo un paciente con nivel normal a ingreso. Al momento del ingreso los niveles de vitamina $D$ fueron más altos que los mostrados al egreso de los pacientes (13.8 versus 12.9) $p=0.37$ sin correlación entre los niveles de vitamina $D$ y mortalidad ni en la duración de estancia intrahospitalaria, pero sí se identificó una relación positiva con los valores de APACHE, SOFA y niveles bajos de vitamina $D$. La deficiencia de vitamina $D$ tiene una elevada prevalencia en los enfermos con sepsis y choque séptico correlacionada con la gravedad y la disfunción orgánica con la que cursan. En este estudio no se encontró relación estadísticamente significativa con la mortalidad y días de estancia hospitalaria. ${ }^{5}$ Teijeiro y colaboradores realizaron un estudio con el fin de determinar la utilidad de APACHE II, SOFA, PCR y VSG al ingreso en la UTIA como predictores de deficiencia de vitamina $D$, y de conocer la incidencia de deficiencia de vitamina $D$ en la UCl, su asociación con la mortalidad y estancia intrahospitalaria. Se realizó un estudio observacional, longitudinal, analítico, prospectivo de casos y controles. Se incluyeron 46 pacientes de la UTIA de enero a julio de 2014. Se determinó PCR, VSG, APACHE II y SOFA así como niveles de 25-hidroxivitamina D al ingreso y al séptimo día. Se dividió a los participantes en dos grupos: deficientes y no deficientes de vitamina $D$, y se establecieron medidas de asociación y se obtuvo como resultado que APACHE II, SOFA, PCR y VSG no fueron de utilidad para predecir la deficiencia de vitamina $D$. Encontramos diferencia significativa en el tiempo de estancia intrahospitalaria $(p=0.024)$, que fue superior en pacientes con deficiencia severa. La incidencia a las 24 horas fue de $80 \%$. Se observó una alta incidencia de deficiencia de vitamina $D$ y una asociación con el incremento de la estancia hospitalaria, lo que justifica la medición de niveles 25-OHVD en los pacientes críticos. A 46 pacientes (68\%) se les realizó la determinación de la 25-OHVD al ingreso, la distribución por género fue $50 \%$ para masculino/femenino. El promedio de edad al ingreso a la UTIA fue de 60 años, con mínimo 19 y máximo 92, con una distribución anormal. El diagnóstico principal más frecuente fue complicaciones quirúrgicas $(23.9 \%)$, seguido de sepsis $(21.7 \%)$ y enfermedad cardiovascular (15.2\%). La media del puntaje APACHE Il obtenido fue $19.2(2-44)$ y el puntaje en el score de SOFA fue 6.33 (0-14); $23.9 \%$ de los enfermos se clasificaron en el grupo IV de APACHE II, siendo éste el más frecuente con mortalidad esperada de $36.71 \%$, mientras que $44 \%$ de la población se ubicó en los grupos de alto riesgo de acuerdo con la escala SOFA (> nueve puntos), con tasas de mortalidad desde $33 \%$ hasta $95 \%$ para aquéllos con SOFA $>11$.

En cuanto al estatus de vitamina $D$ al ingreso, sólo $4.3 \%$ de los pacientes registraron niveles de suficiencia. La media en los niveles de 25-OHVD al ingreso fue de $14.87 \mathrm{ng} / \mathrm{mL}$; valor máximo reportado en $44 \mathrm{ng} / \mathrm{mL}$ y mínimo en $3 \mathrm{ng} / \mathrm{mL}$, 17 tuvieron estancias hospitalarias $>$ siete días, lo que permitió repetir los niveles de 25OHVD al séptimo día; 35\% tenían deficiencia severa de vitamina $\mathrm{D}$. La media de variación entre las determinaciones de 25-OHVD a las 24 horas de ingreso versus el día siete de estancia hospitalaria fue un decremento de $-1.56 \mathrm{ng} / \mathrm{mL}$. La mortalidad a 90 días del estudio fue de $24 \%$, el tiempo promedio de estancia en la UTIA fue de 
6.43 días, con estancia intrahospitalaria total de 19.57 días en promedio. ${ }^{6}$

\section{MATERIAL Y MÉTODOS}

El objetivo principal de este estudio es determinar la frecuencia de suficiencia, insuficiencia y deficiencia de vitamina $D$ en los pacientes que ingresan a la unidad de cuidados intensivos con el diagnóstico de sepsis.

Como objetivos secundarios: establecer una correlación entre niveles séricos de vitamina $\mathrm{D}$, y días de estancia intrahospitalaria; y establecer una correlación entre niveles séricos de vitamina $D$, y muerte intrahospitalaria.

Se realizó un estudio observacional, trasversal y retrospectivo. Se incluyeron todos los pacientes que hayan ingresado a la unidad de cuidados intensivos adultos (UCIA) de un hospital de tercer nivel, que tuvieran medición de niveles séricos de vitamina $D$ y diagnóstico de sepsis que cumplieran con los criterios de inclusión. Se eliminaron los pacientes con antecedentes de consumo de polivitaminas, o consumo previo de vitamina $D$, diagnóstico de enfermedad renal crónica o embarazo en curso.

Las variables recolectadas en la unidad de cuidados intensivos son: sexo, edad, foco de infección, días de estancia intrahospitalaria, APACHE II, SOFA, defunción, choque, paciente oncológico, paciente inmunodeprimido, ventilación mecánica, afiliación ISSSTELEON, nivel de vitamina D, índice de masa corporal, hemoglobina, hematocrito, leucocitos, neutrófilos, linfocitos, plaquetas, glucosa, creatinina, BUN, urea, colesterol, triglicéridos, calcio, fósforo, bilirrubina total, AST, ALT, albumina, sodio, potasio, cloro, PCR, procalcitonina, $\mathrm{Ph}$ y lactato.

\section{Análisis estadístico}

Los resultados de las características de los pacientes se expresarán como medidas de tendencia central y dispersión (de acuerdo con la distribución de la muestra). Se utilizará la prueba de t de Student para las variables numéricas, $U$ de Mann-Whitney para las variables de distribución no paramétrica, y para las variables cualitativas la prueba de $\chi^{2}$. Para establecer el grado de asociación de dos variables (correlación) se utilizará el coeficiente de asociación de Pearson, para determinar la significancia estadística se considerará un intervalo de confianza de $95 \%$, y un valor de $p=$ menor de 0.05 . Se utilizará software estadístico IBM SPSS Statistics Versión 22.0.

\section{Comité de ética y confidencialidad}

Por las características de este estudio, no se espera que cause daño físico o moral a los pacientes del mismo.

\section{RESULTADOS}

Se realizó la revisión de expedientes de los pacientes que ingresaron a la Unidad de Terapia Intensiva del Hospital San José Tecnológico de Monterrey durante el periodo comprendido de junio de 2018 a marzo de 2019, se revisó de manera consecutiva, y se seleccionó a todos los pacientes que contaron con diagnóstico de sepsis y medición de niveles de vitamina $D$ al ingreso. Se revisó un total de 492 expedientes, de los cuales 30 pacientes cumplieron los criterios de inclusión de estudio, se excluyeron 12 pacientes cuyos registros no se encontraron en expediente electrónico, y 75 pacientes que tenían diagnóstico de sepsis, pero no medición de niveles de vitamina $D$.

Las características de la población general fueron las siguientes: edad media de $56 \pm 15$ años, con predominio del sexo masculino $70 \%(n=21)$, con afiliación a servicios de salud de ISSSTELEON 36.7\% $(n=11)$, con antecedentes de patología oncológica de base en $26.7 \%(n=8)$ e inmunodepresión en 30\% (n=9). Al ingreso a la unidad de terapia intensiva $73.3 \%(n=22)$ se encontraron en estado de choque, $70 \%(n=21)$ bajo ventilación mecánica, con un promedio en las escalas de mortalidad de 16 puntos en APACHE II con $25 \%$ de mortalidad y ocho puntos en SOFA con 15 a $20 \%$ de mortalidad.

Con los siguientes focos de infección identificados al ingreso, abdominal $23.3 \%(n=7)$, pulmonar $46.6 \%(n$ $=14)$, viral $3.3 \%(n=1)$, genitourinario $20 \%(n=6)$, neurológico 3.3\% $(n=1)$, articulación 3.3\% con estancia intrahospitalaria en UCIA en promedio de 14 días, y mortalidad de $26.7 \%(n=8)$.

Los pacientes en el estudio tienen sobrepeso con un promedio de IMC de 26, en biometría hemática en promedio con hemoglobina de 11.2; hematocrito 33.5; leucocitos 18,883; neutrófilos 16,559; linfocitos 1,457; plaquetas 118,336 . Sin datos de coagulopatía con INR de 1.34. Con alteración metabólica con glucosa 224, colesterol 113, triglicéridos 181. A nivel renal con tendencia a la elevación de azoados con creatinina de 1.53, BUN 30, urea 65, sin alteraciones electrolíticas de relevancia con sodio 137, potasio 4.1, cloro 105, calcio total 8.4, fósforo 3.6, conservando estado ácido base con $\mathrm{Ph} 7.32$, con hiperlactatemia 2.46. En pruebas funcionales hepáticas sin alteraciones de relevancia con bilirrubina total de 1.05, con hipoalbuminemia 2.72, AST 51 y ALT 35.

En los niveles de vitamina $D$ se obtuvo un promedio de $12 \pm 5$, con un valor máximo de 28.3, y un valor mínimo de 3.5. Se realizó clasificación de los pacientes de acuerdo a nivel de vitamina $\mathrm{D}$ en suficiencia (mayor de 30 ), insuficiencia (de 10 a 30) y deficiencia (menor de $10)$, obteniendo $0 \%(n=0)$ en suficiencia, insuficiencia de $53 \%(n=16)$ y $47 \%(n=14)$ en deficiencia (Figura 1$)$. 
De acuerdo con los niveles obtenidos de vitamina $D$, únicamente se encontraron dos grupos, siendo insuficiencia y deficiencia, por lo que se dividen en dos grupos: la población, los pacientes que obtuvieron menos de $10 \mathrm{ng} / \mathrm{mL}$ y los que obtuvieron más de $10 \mathrm{ng} / \mathrm{mL}$. Al realizar la comparativa entre los dos grupos no se observó diferencia significativa en edad, días de estancia intrahospitalaria, SOFA, siendo los valores de $p=$ $0.724,0.755,0.241$ respectivamente. El nivel medio de vitamina $D$ en el grupo de menos de $10 \mathrm{ng} / \mathrm{mL}$ fue de 7.87 y en el grupo superior a $10 \mathrm{ng} / \mathrm{mL}$ fue de 15.93 , con un valor de $p=0.000$. De manera relevante se encontró significancia estadística en puntaje en escala de mortalidad de APACHE II con un puntaje de media de 19.5 puntos en el grupo menor de $10 \mathrm{ng} / \mathrm{mL}$ y de 14.3 puntos en el grupo mayor de $10 \mathrm{ng} / \mathrm{mL}$, con una mortalidad esperada por puntuación de 25 y $15 \%$ respectivamente, con un valor de $p=0.033$ (Figura 2).

En la biometría hemática no se observan valores estadísticamente significativos, pero presentan en el grupo de menos de 10 de vitamina $D$ valores menores de hemoglobina y hematocrito 10.31 vs. 12.01 y 31.34 vs. 35.52 , se encuentran más leucocitosis y neutrofilia en el grupo menor de 10 de vitamina D 22,662 vs. 15,612 y 20,308 vs. 13,354 . A nivel metabólico con mayor alteración con tendencia a la hiperglucemia en el grupo menor de 10, con 290 vs. 160, y con mayor hipertrigliceridemia con 217 vs. 149.

Se realiza correlación de defunción con diferentes grupos sin diferencia estadísticamente significativa en los grupos correspondientes a edad, sexo y afiliados a servicio de salud de ISSSTELON, se encuentran con valores estadísticamente significativos los pacientes con padecimiento oncológico de base con defunción en $75 \%$, con inmunosupresión de $66.7 \%$, choque $36.4 \%$, con valores de $p=$ de $0.000,0.0001,0.046$, respectivamente.

En cuanto a defunción asociada a nivel de vitamina D por grupos, existe una diferencia importante en porcentaje de mortalidad de $42.90 \%$ en el grupo menor de 10 y de $12.50 \%$ en el grupo mayor de 10 , pero estadís-

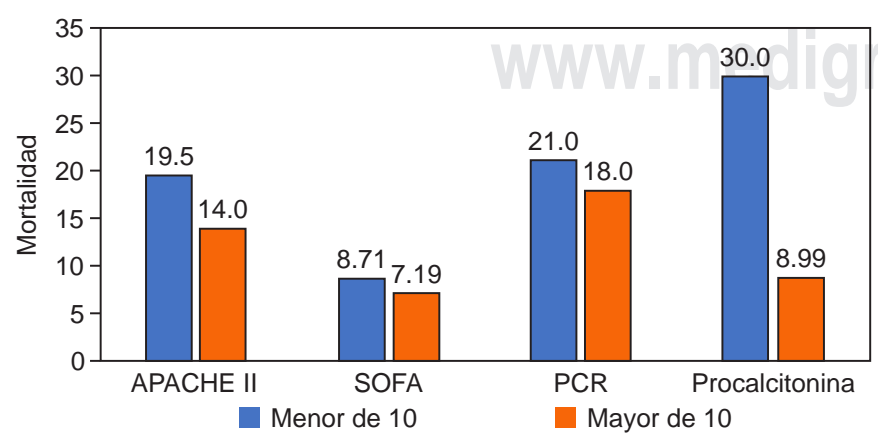

Figura 2: Marcadores de inflamación y escalas de mortalidad. ticamente no muestra significancia con una $p=0.061$, pero a nivel clínico es importante tenerlo en cuenta.

Se realiza prueba de Long Rank, siendo estadísticamente significativa con una $p=0.021$, y se realiza curva de Kaplan Meyer con una diferencia importante en supervivencia a los 60 días de $90 \%$ en el grupo mayor de 10 vs. $20 \%$ en el grupo menor de 10.

\section{DISCUSIÓN}

De acuerdo con la descripción general de la población en comparación con la epidemiología internacional por Angus y colaboradores, se mantiene la cifra promedio con un comportamiento similar en la unidad de terapia intensiva con $26.7 \%$ de mortalidad y a nivel nacional, siendo similar al estudio de Carrillo y su equipo con $30 \%$ de mortalidad, en comparación únicamente con epidemiología proveniente de Estados Unidos. Paoli y colegas establecen una mortalidad del choque séptico en $34.5 \%$ siendo similar. Pero existe una prevalencia diferente comparada a nivel global, con $21 \%$ de casos con diagnóstico de sepsis al ingreso a la UCIA vs. $10 \%$ en EUA vs. $27 \%$ en Reino Unido.

No existe una diferencia importante en mortalidad comparada con la epidemiología de otros países siendo en promedio de $30 \%$, tomando en cuenta la prevalencia hay una diferencia importante comparada con los Estados Unidos con una diferencia de $10 \%$, que es el doble, pero cabe mencionar que cuenta con mayor número de camas censadas por unidad de UCIA, lo que permite ingresar mayor cantidad de pacientes con distintos diagnósticos de ingreso, lo cual hace que disminuya el porcentaje de la prevalencia al tener mayor capacidad de ingreso de pacientes.

Se realiza comparación demográfica con dos estudios previos realizados en el Hospital Juárez de la Ciudad de México, por Jiménez y colaboradores y por el Hospital San José Tecnológico de Monterrey, por Teijeiro y su equipo, encontrando una distribución similar de predominio de sexo masculino así como una edad promedio de 50 a 60 años de edad, aunque la población estudiada por Jiménez es distinta en cuanto a sitio de valoración, ya que los pacientes pertenecen al área de medicina interna, y Teijeiro y el estudio actualmente realizado se llevó a cabo en un área de cuidados intensivos, por lo que se asocia a menor mortalidad perteneciendo al grado III de APACHE II los pacientes estudiados en el Hospital Juárez, y los dos grupos estudiados en la Unidad Cuidados Intensivos Adultos del Hospital San José Tecnológico de Monterrey que cuentan con mayor grado de mortalidad (25\%), pertenecen al grado IV de APACHE II. Los pacientes estudiados en piso de medicina interna contaron con menor proporción de pacientes en estado de choque siendo 25 vs. $73 \%$ de los pacientes del estudio actual, por lo que corresponde 
también que se asocie a menor grado de mortalidad en piso de medicina interna. Su sitio de infección fue predominantemente de neumonía en el estudio de Jiménez con una proporción importante de $78 \%$, siendo que la Unidad Cuidados Intensivos Adultos del Hospital San José Tecnológico de Monterrey cuenta con menor porcentaje de foco de infección por neumonía con $46 \%$, pero cuenta con una proporción importante de infección de origen abdominal y genitourinario.

El estatus de la vitamina $D$ en el estudio realizado es de $12.2 \mathrm{ng} / \mathrm{mL}$, comparado con los niveles establecidos por el Instituto de Medicina de Estados Unidos, la Sociedad Americana de Endocrinología y la Encuesta Nacional de Nutrición de Estados Unidos se encuentra muy por debajo de los niveles de normalidad establecidos para una salud óptima. Comparado con los estudios realizados en México se ubica en valores similares, a pesar de que el estudio realizado por Jiménez se llevó a cabo en piso de medicina interna y que en el estudio realizado por Teijeiro se incluyeron pacientes con diversas patologías y no únicamente pacientes con sepsis, se obtuvo un resultado similar, el resultado más bajo de los tres estudios, teniendo en común que son pacientes en estado crítico y con un proceso de inflamación activo, y que en nuestro estudio no tuvimos el mayor puntaje de APACHE comparado entre los tres, pero tuvimos a la mayoría de la población en estado de choque al ingreso a la UCIA, por lo que puede ser de importancia al obtener el puntaje más bajo de vitamina D. Teniendo en cuenta que los tres estudios realizados en el país son en fechas distintas, y que de acuerdo con ENSANUT son los dos estados con mayor (Nuevo León) y menor (Ciudad de México) nivel de vitamina $D$, no existe diferencia entre los niveles de vitamina $D$, siendo similares al estar en un proceso de estrés físico y de gravedad, por lo que las diferencias multifactoriales para determinar que una persona tenga cierto nivel de vitamina $\mathrm{D}$ parece no tener relevancia al momento de estar en un proceso crítico. Es relevante el valor obtenido entre los pacientes afiliados a los servicios de salud de ISSSTELON vs. pacientes privados, ya que no existe diferencia significativa en los niveles de vitamina $D$ con una $p=0.302$, estableciendo que no hay una diferencia a pesar de ser población de distinto estrato socioeconómico.

En el estudio realizado por Jiménez y nuestro estudio se obtuvo que los pacientes con diagnóstico de sepsis en estado crítico tendrán una larga estancia intrahospitalaria (igual o mayor de nueve días) con un promedio de 14 días, esto tiene una implicación de importancia en el gasto aplicado a cada paciente por día en una unidad de cuidados intensivos, ya sea un servicio público o privado, por ejemplo, el costo promedio mínimo de un paciente en UCIA de un hospital privado de tercer nivel es de aproximadamente de $\$ 50,000.00$ pesos por día, con un promedio total mínimo de $\$ 700,000.00$ pesos por ElH si al ingreso cuenta con diagnóstico de sepsis. A diferencia del estudio de Teijeiro, en la población de dicho estudio predominaron pacientes en estado y cuidados postquirúrgicos, con un promedio de seis días con un costo total mínimo de $\$ 300,000.00$, lo que es relevante, ya que el gasto se reduce $58 \%$. Sin embargo, al realizar prueba estadística, no se encuentra relevancia significativa al correlacionar niveles de vitamina $D$ y estancia intrahospitalaria con una $p=0.938$.

En mortalidad no hubo diferencia entre diversos estudios, en el estudio realizado hubo una mortalidad de $26.7 \%$, y haciendo correlación directa entre vitamina $D$ y defunción no se observa una correlación estadísticamente significativa con una $p=0.265$. Posteriormente, se procedió a realizar pruebas estadísticas por agrupación y correlación con defunción, siendo la agrupación por edad no estadísticamente significativa, por lo que no es una determinante importante al ingreso a la UCIA con diagnóstico de sepsis, razón por la que no presenta mayor grado de mortalidad a mayor edad con una $p=0.0783$. En sexo no existe diferencia entre si un paciente es hombre o mujer $p=0.0719$, de manera relevante es la presencia de antecedente de enfermedad oncológica e inmunosupresión, ya que tiene una mortalidad muy alta siendo de 75 y $66 \%$, con una $p=0.000$ y una $p=0.001$ respectivamente, y los pacientes que ingresan en estado de choque tienen una mortalidad de $36.4 \%$, y se espera una mortalidad alta con una $p=0.046$, pero lo más relevante es que los pacientes que ingresaron a la UCIA sin estado de choque tuvieron $0 \%$ de mortalidad.

Se realiza la división de acuerdo al nivel de vitamina D siendo el grupo menor de $10 \mathrm{ng} / \mathrm{mL}$ y el grupo mayor de $10 \mathrm{ng} / \mathrm{mL}$, y se cuenta con información relevante con impacto en la mortalidad con un porcentaje de $42.9 \%$ de mortalidad vs. $12.5 \%$ de mortalidad respectivamente, con una $p=0.061$, que estadísticamente no cumple significancia, pero la muestra es pequeña, por lo cual no tiene poder suficiente para alcanzar un valor estadísticamente significativo, razón por la que se necesitaría incrementar el tamaño de muestra para que se obtenga un valor de $p$ menor de 0.05 , pero clínicamente la información es contundente, ya que aquellos pacientes que ingresen a la UCIA con un valor menor de $10 \mathrm{ng} / \mathrm{mL}$ de vitamina $D$, tendrán una mortalidad superior a $40 \%$. Al no encontrar un valor estadísticamente significativo por correlación, se realiza curva de Kaplan Meier obteniendo una supervivencia a los 60 días de aproximadamente $20 \%$ y se realiza prueba de Long Rank con una $p=$ 0.021 siendo estadísticamente significativa, por lo que en nuestro estudio podemos establecer que los valores inferiores de $10 \mathrm{ng} / \mathrm{mL}$ de vitamina $D$ se correlacionan con mayor mortalidad. Comparado con el estudio de Jiménez hay una diferencia importante debido a que en 
su estudio se define que no hay relación entre niveles de vitamina $D$ y mortalidad, teniendo una media de 14 de los pacientes que fallecieron, mientras que en nuestro estudio la media de los pacientes fallecidos es de 9.7, razón por la cual los pacientes que fallecieron en el estudio de Jiménez se ubicaron en la clasificación de insuficiencia mientras se encontraban en el grupo de deficiencia de vitamina $D$. Y al ser comparado con el estudio de Teijeiro, los datos reportados fueron contradictorios, pues no se encontró relación entre mortalidad y vitamina $\mathrm{D}$; sin embargo, su población es distinta, puesto que son provenientes de quirófano, y únicamente se encuentra con ocho pacientes con sepsis, por lo que su población es heterogénea, y compara la mortalidad dividiendo en grupo de deficiencia y suficiencia sin obtener relación con la mortalidad. En nuestro estudio toma relevancia el hallazgo de la relación de la mortalidad al momento de hacer la división de grupo de insuficiencia vs. deficiencia de vitamina $D$.

Al hallar factores que intervengan en la deficiencia de vitamina $D$, se obtienen diferencias importantes entre los dos grupos de vitamina $D$, teniendo un fenotipo aparente con mayor inflamación encontrando una leucocitosis superior muy marcada en el grupo menor de vitamina $D$ con 22,622 vs. 15,612 , aunque no es estadísticamente significativa $\mathrm{p}=0.135$ así como presencia de anemia con hemoglobina de 10.31 vs. 12.02 vs. 12.01 con una $p=0.15$, con el descontrol metabólico por inflamación más acentuado con niveles de glucosa en rango de descontrol para paciente en estado crítico con 290 vs. 166 con una $p=0.708$. De manera relevante hay una diferencia importante en la cifra de procalcitonina, ya que es superior en el grupo menor de 10 con 30 vs. 8.99 con una $p=0.101$ y directamente en relación con la mortalidad hay una diferencia importante en escala de mortalidad por APACHE II, siendo un valor de 19.5 en el grupo menor de 10 vs. 14.3 en el grupo mayor de 10 con una $p=0.033$, que es estadísticamente significativa, por lo que podemos establecer que existe una relación directa en cuanto a menor nivel de vitamina $\mathrm{D}$ mayor escala de mortalidad y viceversa.

\section{CONCLUSIONES}

- El estatus de los niveles de la vitamina $D$ en los pacientes que ingresan a la UCIA es de $12 \pm 5$ siendo un valor correspondiente en el grado de insuficiencia de vitamina $D$. De la población, $53 \%$ se encontró en grado de insuficiencia y $47 \%$ de la población estudiada se observó en grado de deficiencia.

- No existe correlación con un valor estadísticamente significativo entre los niveles de vitamina $D$ y días de estancia intrahospitalaria. Sin embargo, sí existe una diferencia de importancia por el simple hecho de ingresar a la unidad de cuidados intensivos con diagnóstico de sepsis con un promedio de 14 días de estancia intrahospitalaria.

- En cuanto a mortalidad obtuvimos $26.7 \%$ en la población total, sin obtener un valor estadísticamente significativo con una correlación directa con la vitamina D; sin embargo, al momento de hacer la división por grupo de los niveles de vitamina $\mathrm{D}$, obtenemos una diferencia clínica importante en mortalidad comparando el porcentaje de defunción de los pacientes con valor inferior a $10 \mathrm{ng} / \mathrm{mL}$ siendo de $42.9 \%$ vs. los pacientes con valor superior a $10 \mathrm{ng} / \mathrm{mL}$ de $12.5 \%$, que no alcanza un valor estadísticamente significativo; sin embargo, la población estudiada es pequeña, por lo que sólo se requiere aumentar el tamaño de muestra para obtener un valor estadísticamente significativo. Por tal motivo, podemos sugerir que los pacientes que obtengan un resultado de vitamina $D$ inferior a $10 \mathrm{ng} / \mathrm{mL}$, tendrán mayor mortalidad si ingresan con diagnóstico de sepsis, y una supervivencia a los 60 días de $20 \%$.

- El estudio obtuvo resultados importantes, y puede servir como un estudio piloto para poder continuar con un segundo estudio con una muestra mayor, y valorar principalmente a los pacientes que se encuentran en grado de deficiencia con un valor menor de $10 \mathrm{ng} / \mathrm{mL}$, lo que es relevante, ya que en un futuro estudio puede plantearse a su vez la suplementación de vitamina $D$.

\section{REFERENCIAS}

1. Holick MF. High prevalence of vitamin D inadequacy and implications for health. Mayo Clin Proc. 2006;81(3):353-373. Available from: http://dx.doi.org/10.4065/81.3.353.

2. Flores M, Sánchez-Romero LM, Macías N, Lozada A, Díaz E, Barquera $S$. Concentraciones séricas de vitamina $D$ en niños, adolescentes y adultos mexicanos. Resultados de la ENSANUT 2006. Inst Nac Salud Pública. 2011;1(1):1-29.

3. Institute of Medicine. DRI dietary reference intakes calcium vitamin D. Nutrition Reviews. 2011;62:400-401. Available from: https://academic.oup.com/nutritionreviews/article-lookup/ doi/10.1111/j.1753 4887.2004.tb00011.x.

4. Holick MF, Binkley NC, Bischoff-Ferrari HA, Gordon CM, Hanley DA, Heaney RP, et al. Guidelines for preventing and treating vitamin $\mathrm{D}$ deficiency and insufficiency revisited. $J$ Clin Endocrinol Metab. 2012;97(4):1153-1158.

5. Jiménez Perez Christina Adrián, Carrillo Córdoba Jorge Raúl CER. Prevalencia de la deficiencia e insuficiencia de vitamina $\mathrm{D}$ en pacientes con sepsis y choque séptico en un hospital de tercer nivel. 2018;32(3):126-130.

6. Paradis RT, Martínez SF, Rodríguez IR, Manuel V, Nava S, Quintanilla LB, et al. Utilidad de las escalas APACHE II, SOFA, PCR y VSG al ingreso a la UCI como predictores de deficiencia de vitamina D. Rev Asoc Mex Med Crit Ter Int. 2016;30(2):111-118.

7. Cynthia A. Vitamin D and the immune system. J Rheumatol. 2010;37(3):491-495.

8. Martín-Ramírez JF, Domínguez-Borgua A, Vázquez-Flores AD. Sepsis. Med Int Méx. 2014;30:159-175.

9. Sareen G, S Jack GJ. Advanced nutrition and human metabolism. [Internet]. 5th ed. 2010. Available from: https://www.canada.ca/ content/dam/hc-sc/migration/hc-sc/fn-an/alt_formats/hpfb-dgpsa/ pdf/nutrition/dri_tables-eng.pdf. 
10. Holick MF, Binkley NC, Bischoff-Ferrari HA, Gordon CM, Hanley DA, Heaney RP, et al. Evaluation, treatment, and prevention of vitamin D deficiency: An endocrine society clinical practice guideline. J Clin Endocrinol Metab. 2011;96(7):1911-1930.

11. Rosen CJ. Vitamin D insufficiency. Home Health Care Manag Pract. 2008;21(2):132-134.

12. Bandeira F, Griz L, Dreyer P. Deficiencia de vitamina D: uma perspectiva global. Arq Bras Endocrinol Metabol. 2006;50:640646. Available from: http://onlinelibrary.wiley.com/doi/10.1111/ j.1753-4887.2008.00100.x/full\%5Cnhttp://www.scientificcircle. com/pt/124160/deficiencia-vitamina-d-perspectiva-global/.

13. Venkatram S, Chilimuri S, Adrish M, Salako A, Patel M, DiazFuentes G. Vitamin D deficiency is associated with mortality in the medical intensive care unit. Crit Care. 2011;15(6):R292. Available from: http://ccforum.com/content/15/6/R292.

14. Diamond T, Smerdely P, Kormas N, Sekel R, Vu T, Day P. Hip fracture in elderly men: The importance of subclinical vitamin $D$ deficiency and hypogonadism. Med J Aust. 1998;169(3):138-141.

15. Ochoa-Correa EC, García-Hernández PA, Villarreal-Pérez JZ, Treviño-Garza C, Rodríguez-Balderrama I, Martínez-de Villarreal LE, et al. Deficiencia de vitamina $D$ en madres y neonatos mexicanos. Gac Med Mex. 2017;153(5):559-565.

16. Amrein K, Papinutti A, Mathew E, Vila G, Parekh D. Vitamin D and critical illness: what endocrinology can learn from intensive care and vice versa. Endocr Connect. 2018;7(12):R304-315.

17. Amrein K, Schnedl C, Holl A, Riedl R, Christopher KB, Pachler C, et al. Effect of high-dose vitamin $D 3$ on hospital length of stay in critically ill patients with vitamin D deficiency. JAMA. 2014;312(15):1520-1530.

18. Braun A, Chang D, Mahadevapa K, Gibbons F, Liu Y, Giovannucci ECK. Association of low serum 25-hydroxyvitamin D levels and mortality in the critically ill. Crit Care Med. 2011;39(4):671-677.

19. Matthews R, Ahmed Y, Wilson K, Griggs DDO. Worsening severity of vitamin $D$ deficiency is associated with increased length of stay, surgical intensive care unit cost, and mortality rate in surgical intensive care unit patients. Am J Surg. 2012;204(1):37-43.

20. Higgins DM, Wischmeyer PE, Queensland KM, Sillau SH, Sufit AJ, Heyland DK. Relationship of vitamin D deficiency to clinical outcomes in critically ill patients. J Parenter Enter Nutr. 2012;36(6):713-720.

21. Autier P, Boniol M, Pizot C, Mullie P. Vitamin D status and ill health: A systematic review. Lancet Diabetes Endocrinol. 2014;2(1):76-89.

22. Hewison M. Vitamin D and immune function: an overview. Proc Nutr Soc. 2012;71(1):50-61.
23. Nair P, Venkatesh B, Lee P, Kerr S, Hoechter DJ, Dimeski G, et al. A randomized study of a single dose of intramuscular cholecalciferol in critically ill adults. Crit Care Med. 2015;43(11):2313-2320.

24. Belsky JB, Wira CR, Jacob V, Sather JE, Lee PJ. A review of micronutrients in sepsis: The role of thiamine, I-carnitine, vitamin C, selenium and vitamin D. Nutr Res Rev. 2018;31(2):281-290.

25. Parekh D, Patel JM, Scott A, Lax S, Dancer RCA, D'souza V, et al. Vitamin D deficiency in human and murine sepsis. Crit Care Med. 2017;45(2):282-289.

26. Moromizato T, Litonjua AA, Braun AB, Gibbons FK, Giovannucci E, Christopher KB. Association of low serum 25-hydroxyvitamin D levels and sepsis in the critically ill. Crit Care Med. 2014:42(1):97-107.

27. Shojaei M, Sabzeghabaei A, Valaei Barhagh H, Soltani S. The correlation between serum level of Vitamin $D$ and outcome of sepsis patients; a cross-sectional study. Arch Acad Emerg Med. 2019;7(1):e1. Available from: http://www.ncbi.nlm.nih. gov/pubmed/30847436\%0Ahttp://www.pubmedcentral.nih.gov/ articlerender.fcgi?artid=PMC6377223.

28. Yaghoobi MH, Taher A, Seifrabie MA, Sabahi M, Rahimi-Bashar F. Serum vitamin $D$ level was not associated with severity of ventilator associated pneumonia. Rom J Intern Med. 2019;57(1):55-60. Available from: https://content.sciendo.com/view/journals/rjim/ ahead-of-print/article-10.2478-rjim-2018-0033.xml.

29. Ratzinger $F$, Haslacher $H$, Stadlberger $M$, Schmidt RLJ, Obermüller M, Schmetterer KG, et al. 25(OH)D and 1,25(OH) $\mathrm{D}$ Vitamin $\mathrm{D}$ fails to predict sepsis and mortality in a prospective cohort study. Sci Rep. 2017;7:1-10. Available from: http://dx.doi. org/10.1038/srep40646.

Patrocinios: Ninguno.

Relación de conflicto de intereses: Los autores declaran no tener conflicto de intereses.

\section{Correspondencia:}

Héctor Antonio López Morán

Avenida Frida Kahlo Núm. 180,

Haciendas de la Sierra, 66260,

San Pedro Garza García, Nuevo León.

Tel: 81-8368-7777

E-mail: hector_lopez_moran@hotmail.com 